\title{
O PAPEL DO PROBLEMA NO ENSINO DE CIÊNCIAS: COMPREENSÕES DE PESQUISADORES QUE SE REFERENCIAM EM VYGOTSKY
}

\begin{abstract}
RESUMO: Investigamos como pesquisadores brasileiros do ensino de ciências, referenciados na perspectiva vygotskyana, concebem e caracterizam a noção de problema e seu critério de seleção em atividades didático-pedagógicas. Foram realizadas entrevistas, analisadas por meio da Análise Textual Discursiva, com cinco pesquisadores da área de ensino de Ciências que utilizam como referência pressupostos de Vygotsky. Os resultados indicam que os critérios utilizados pelos pesquisadores para a escolha de problemas que orientam atividades didático-pedagógicas estão calcados, em sua maioria, na conceituação científica. No entanto, constatou-se um movimento de transição, por parte de pesquisadores, de que o problema passa a ter um papel na seleção e estruturação de conceitos científicos, o que se aproxima da noção de problema presente na obra de Vygotsky.
\end{abstract}

Palavras-chave: Função de problema. Vygotsky. Ensino de ciências.

THE ROLE OF THE PROBLEM IN SCIENCE EDUCATION: UNDERSTANDINGS OF RESEARCHERS THAT HAS REFERENCE IN VYGOTSKY

ABSTRACT: In this article, it is investigated how Brazilian science education researchers, referenced in the Vygotskian perspective, conceive and characterize the notion of problem and its selection criteria in didactic and pedagogical activities. Interviews were conducted with five researchers in science education who use as reference Vygotsky's assumptions, which were analyzed by Discursive Textual Analysis. The results indicate that the criteria used by researchers to choose problems that guide the didactic and pedagogical activities are mostly attached to scientific concepts. However, it was found that some researchers have come to perceive that the problem has a role in the selection and organization of scientific concepts. Such perspective is closer to the notion of problem presented in the work of Vygotsky.

Keywords: Problem function. Vygotsky. Science education.

\section{Simoni Tormohlen Gehlen* \\ Demétrio Delizoicov**}

\author{
*Doutora em Educação Científica \\ e Tecnológica pela Universidade \\ Federal de Santa Catarina (UFSC) \\ e professora do Departamento de \\ Ciências Exatas e Tecnológicas \\ da Universidade Estadual de \\ Santa Cruz/ Ilhéus (UESC). \\ E-mail: simonigehlen@yahoo.com.br \\ **Doutor em Educação pela \\ Universidade de São Paulo(USP). \\ Professor adjunto da Universidade \\ Federal de Santa Catarina(UFSC). \\ E-mail: demetrio@ced.ufsc.br
}




\section{INTRODUCְÃO}

O pensamento de Vygotsky tem sido utilizado no Brasil de forma significativa por parte da pesquisa em educação, psicologia e educação em ciências. Essa disseminação dos pressupostos vygotskyanos é constatada por diversos estudos, como os realizados por Silva e Davis (2004), que analisam a produção na área de Educação e Psicologia, tendo como referência os Cadernos de Pesquisa, revista da Fundação Carlos Chagas, nas décadas de 1980 e 1990; por Freitas (2004), que discute a apropriação do referencial vygotskyano nos trabalhos apresentados durante o período que vai da $21^{\mathrm{a}}$ até a $26^{\mathrm{a}}$ Reunião Anual da Associação Nacional de Pós Graduação e Pesquisa em Educação (ANPEd), de 1998 a 2003; e por Sarmento (2006), que analisa os pressupostos vygotskyanos presentes em teses, dissertações e periódicos da área de educação no período de 1986 a 2001.

No ensino de ciência, a difusão da abordagem vygotskyana é constatada por Gehlen, Schoeder e Delizoicov (2007) que, ao analisarem trabalhos publicados no I e V Encontro Nacional de Pesquisa em Educação em Ciências (ENPEC), sinalizam o significativo número de produções acadêmicas que utilizam as ideias de Vygotsky em diferentes contextos e leituras, ampliando, cada vez mais, o interesse desse referencial. No ensino de Física, por exemplo, Gehlen, Machado e Auth (2009) apontam a extensão e a disseminação desse autor como aporte teórico em estudos apresentados no Simpósio Nacional de Ensino de Física, nas edições de 2003, 2005 e 2007.

De forma mais ampla, os pressupostos de Vygotsky têm permeado diversas discussões na educação em ciências, como a elaboração e desenvolvimento de propostas curriculares (MALDANER, 2007; AUTH et al., 2005), o papel da linguagem no processo de ensino-aprendizagem (SOARES e AGUIAR, 2008; MORTIMER e SCOT'T, 2002), a motivação relacionada aos processos interativos em sala de aula (MONTEIRO e GASPAR, 2007) e a inserção da Física Moderna e Contemporânea no Ensino Médio (PEREIRA, OSTERMANN e CAVALCANTI, 2011; OSTERMANN et al., 2009).

Essa significativa presença do pensamento vygotskyano como aporte teórico na pesquisa em educação em ciências direcionou o trabalho de Gehlen (2009) acerca de obras de Vygotsky utilizadas no ensino de ciências, em que foram identificados aspectos relacionados à dimensão epistemológica da noção de problema. Contudo, a autora constata que Vygotsky não esclarece a abordagem desses problemas no contexto educacional.

Nesse sentido, o presente estudo tem por finalidade identificar se a pesquisa em educação em ciências, ao utilizar a perspectiva vygotskyana em seus estudos, apresenta alguma relação com a dimensão epistemológica do problema presente na obra de Vygotsky. Investigamos como pesquisadores brasileiros da área de ensino de ciências, referenciados nas ideias de Vygotsky, concebem e caracterizam o problema e sua função em atividades didático-pedagógicas, identificando critérios na seleção de problemas. Para tal, foram realizadas entrevistas semiestruturadas com pesquisadores 
que publicaram pelo menos um trabalho, utilizando a abordagem vygotskyana, nas atas das seis primeiras edições do ENPEC, no período de 1997 e 2007.

\section{A função do problema na obra de Vygotsky e em atividades didático-pedagógicas}

O estudo realizado por Gehlen (2009) sobre algumas obras de Vygotsky aponta que o surgimento e o desenvolvimento de conceitos são proporcionados por problemas que estão relacionados com o processo de humanização. Dessa forma, a proposição de Vygotsky, ao considerar a assimilação do conhecimento científico como condição para o desenvolvimento cognitivo, insere-o no contexto do processo de humanização da espécie, cuja gênese seria o trabalho consciente, no sentido marxista, decorrente de problemas com os quais o homem vai se constituindo.

Para a autora, a noção de problema nos estudos de Vygotsky está diretamente vinculada ao processo de humanização, e na perspectiva epistemológica está relacionada ao objeto do conhecimento (fonte do saber e produto do saber). Isto é, o problema assume um papel na gênese da criação e apropriação de signos por parte dos sujeitos, assim como é o mediador nas relações entre sujeito e objeto do conhecimento. Essa função e noção de problema também estão presentes no processo de construção da ciência, em que o problema, segundo Bachelard (1977), é a gênese da produção de novos conceitos científicos, bem como da disseminação desses conceitos.

O estudo também aponta que apesar de Vygotsky ter atribuído importância ao problema em sua teoria, não explicita quais características ele necessita ter para ser abordado no processo de ensino-aprendizagem. Além disso, Vygotsky não apresenta os critérios de seleção de problemas, apenas os produtos do seu enfrentamento, isto é, a conceituação científica, dado o papel que ela desempenha no desenvolvimento cognitivo. Assim, Vygotsky não esclarece a maneira pela qual esses problemas podem ser eleitos e nem como eles devem ser abordados, como mediadores, no contexto pedagógico (GEHLEN, 2009).

Gehlen e Delizoicov (2011) ampliam suas investigações para o contexto do ensino de ciências e identificam o papel do problema em atividades didático-pedagógicas envolvendo trabalhos publicados no ENPEC, durante o período de 1997 a 2007, que apresentam como referência a abordagem vygotskyana. Em um primeiro momento, os autores identificaram as obras de Vygotsky nas referências bibliográficas dos trabalhos publicados nas seis primeiras edições do ENPEC. Nelas, foi identificado um total de 174 (7,5\%) trabalhos que usaram obras de Vygotsky como referência, dos quais 44 (25\%) foram selecionados para análise, já que explicitavam elementos em que o problema apresentava um papel no processo didático-pedagógico.

Além desse critério para a seleção dos trabalhos, Gehlen e Delizoicov (2011) consideraram, também, se o problema ao qual os trabalhos se referiam apresentava alguma função na estruturação de práticas educativas. Foram organizados seis grupos, Interações discursivas; Resolução de problemas; Situações de vivência; Temas transversais; Problema como seleção e estruturação de conceitos; e Problematização. Esses 
grupos, embora não excludentes entre si, foram utilizados como critério único, ou seja, cada trabalho foi elencado em apenas um grupo. No Quadro 1 é possível constatar a distribuição dos trabalhos nos grupos:

Quadro 1: Distribuição dos trabalhos selecionados por grupo (GEHLEN, 2009).

\begin{tabular}{|c|c|c|}
\hline \multirow{2}{*}{ Grupos } & \multicolumn{2}{|c|}{ Total de Trabalhos } \\
\cline { 2 - 3 } & $\mathbf{N}^{0}$ & $\%$ \\
\hline Problematização $^{1}$ & 11 & 25 \\
\hline Interações discursivas $^{*}$ & 11 & 25 \\
\hline Resolução de problemas & 7 & 15,9 \\
\hline Temas transversais & 6 & 13,6 \\
\hline Situações de vivência & 5 & 11,4 \\
\hline Problema como seleção e estruturação de conceitos & 4 & 9,1 \\
\hline Total & $\mathbf{4 4}$ & $\mathbf{1 0 0}$ \\
\hline
\end{tabular}

A partir da análise desses grupos, Gehlen e Delizoicov (2011) e Gehlen (2009) revelam que o problema na pesquisa em educação em ciências tem se apresentado de duas formas: estruturação curricular, em que o conteúdo programático é organizado com base em temas, e artifício didático-pedagógico, vinculado especialmente à conceituação científica. No entanto, os autores apontam que os estudos vinculados a esses grupos não apresentam elementos suficientes que identificam os critérios utilizados na seleção de problemas a serem abordados em práticas pedagógicas. Com a finalidade de aprofundar como essas duas formas vêm sendo empregadas pelos distintos grupos, ampliou-se a investigação por meio de entrevistas semiestruturadas com pesquisadores da área de educação em ciências, integrantes de cada grupo.

\section{ENCAMINHAMENTO METODOLÓGICO}

Além da análise dos trabalhos dos seis grupos identificados no ENPEC (GEHLEN e DELIZOICOV, 2011), considerou-se importante obter um leque maior de informações que auxiliassem na configuração da função do problema no processo educacional no momento em que foi realizada uma entrevista semiestruturada com cinco pesquisadores, cada um deles pertencente a um dos grupos: Interações discursivas; Resolução de problemas; Situações de vivência; Temas transversais; Problema como seleção e estruturação de conceitos. Optou-se por entrevistar o pesquisador cuja autoria constava em mais de um trabalho do grupo e também que apresentava características que sugeriam ter sido ele o orientador dos trabalhos. É importante 
destacar o fato de que mesmo que o pesquisador entrevistado seja um componente de um grupo, não podemos afirmar que a sua compreensão sobre o tema é a mesma de outros autores também pertencentes a esse grupo . No entanto, ele representa uma concepção sobre a função dos problemas na sua relação com o processo educacional, particularmente ao ter Vygotsky como uma referência.

A entrevista tinha como objetivo investigar os critérios utilizados pelos pesquisadores para escolha dos problemas identificados nos trabalhos publicados no ENPEC e a eventual articulação destes com alguns fragmentos da obra de Vygotsky.

As questões da entrevista seguiram, sempre que possível, o protocolo explicitado no Quadro 2, a seguir:

\section{Quadro 2: Questões para entrevista}

\section{Principais questões para entrevista}

a) Em seus trabalhos publicados no ENPEC, que critérios você utiliza para escolher os problemas?

b) Que articulações, eventualmente, você explicitaria entre esses critérios e os fragmentos abaixo?

[...] a formação dos conceitos surge sempre no processo de solução de algum problema que se coloca para o pensamento do adolescente. Só como resultado da solução desse problema surge o conceito (VYGOTSKY, 2001. p.237).

[...] a capacitação especificamente humana para a linguagem habilita as crianças a providenciarem instrumentos auxiliares na solução de tarefas difíceis, a superar a ação impulsiva, a planejar uma solução para um problema antes de sua execução e a controlar seu próprio comportamento (VYGOTSKY, 1998, p.38).

A análise das entrevistas foi realizada por meio da Análise Textual Discursiva (MORAES e GALIAZZI, 2007), que tem sido utilizada por alguns estudos no ensino de ciências como uma ferramenta metodológica (CIRINO e SOUZA, 2010; LINDEMANN, 2010; TORRES et al., 2008; GONÇALVES e MARQUES, 2006). A partir dessa dinâmica, foram realizadas as seguintes etapas: unitarização - realização da fragmentação de trechos das entrevistas em que os pesquisadores fazem referência ao termo problema, emergindo, assim, unidades de significado; categorias temáticas - as unidades de significado foram agrupadas segundo suas semelhanças semânticas e discutidas no contexto de categorias a priori, que foram elaboradas por Gehlen e Delizoicov (2011) a partir da análise de estudos publicados no ENPEC que fazem referência ao termo problema; comunicação - foram elaborados textos, descritivos e interpretativos (metatextos), acerca das categorias temáticas que foram abordadas no contexto dos grupos Interações discursivas, Resolução de problema, Situações de vivência, Temas transversais e Problema como seleção e estruturação de conceitos (GEHLEN, 2009).

As concepções dos pesquisadores acerca dessas questões são apresentadas a seguir, articuladas à análise de cada um dos grupos. A identificação dos pesquisadores deu-se pelo sistema alfanumérico E1, E2,...En, preservando sua identidade. 


\section{INTERACִÕES DISCURSIVAS}

Esse grupo reúne trabalhos publicados no ENPEC que abordam a noção de problema tendo como foco as interações entre sujeitos, que se dão no processo de construção de determinados conhecimentos científicos mediante a utilização da linguagem, no contexto de sala de aula (GEHLEN e DELIZOICOV, 2011). O pesquisador representante desse grupo, ao se posicionar sobre os critérios utilizados para a escolha de problemas em seus trabalhos, aponta que:

Em particular, estamos trabalhando muito com situações controversas, um problema, uma situação que apresenta aspectos diferentes que podem ser trazidos à baila, e neste momento em que há estes aspectos diferentes que você instala uma dialogia. [Nas controvérsias] existem pontos de vista diferentes, há pontos que são compartilhamentos e o professor precisa explicitar onde há esses compartilhamentos, geralmente é o conhecimento de base que é compartilhado ou o conhecimento de base que o professor gostaria que fosse compartilhado. A partir daí, preenchendo as lacunas, porque às vezes os pontos de vista aparecem em função das lacunas, esses são os indicadores que podemos ver, é a controvérsia (E1 - grifo nosso).

É importante ressaltar que não há referência às controvérsias nos trabalhos do ENPEC vinculados a esse grupo (GEHLEN e DELIZOICOV, 2011). No entanto, é explicita a relação que o pesquisador E1 realiza entre as controvérsias e a ferramenta analítica proposta por Mortimer e Scott (2002):

[...] a ferramenta do Mortimer tem ajudado porque a gente faz momentos de dialogia em que você sempre vai ter no mínimo dois pontos: o ponto de vista da ciência e o do senso comum. Ao invés de você negar os diferentes pontos, você tos traz para a sala de aula, os valoriza e dialoga sobre eles (E1).

$\mathrm{Na}$ visão de E1, a controvérsia caracteriza uma situação que apresenta diferentes pontos de vista. Por exemplo, em uma mesma situação há explicações tanto da ciência como do senso comum. Essa configuração da controvérsia indica que ela está em uma dimensão conceitual, aspecto que é confirmado pelo próprio pesquisador:

Ela [controvérsia] é principalmente conceitual. É muito difícil você trazer uma controvérsia [...] na Física que não seja conceitual. Primeiro porque para você instalar uma situação argumentativa você tem que compartilhar, tem que ter uma assimetria. Senão, ela parte já de um discurso de autoridade, por isso a valorização do senso comum (E1).

Fica explícito, na fala do investigado, que o problema está relacionado ao processo de formação de conceitos. O foco de discussão, isto é, o problema em questão, é uma situação que até pode fazer parte da vivência dos educandos, mas está, especialmente, vinculada à conceituação científica. Sendo assim, os critérios de seleção dos problemas caracterizados como controvérsias são basicamente 
conceituais. Também é importante destacar que para o pesquisador E1 esse critério apresenta relações com os fragmentos da obra de Vygotsky, presentes no roteiro da entrevista (Quadro 2), ao enfatizar que:

[...] a instalação e o gerenciamento de uma situação controversa é a atividade do professor, e essa atividade nem sempre é compartilhada porque a atividade distribui as ações e às vezes só um gestor sabe qual é o final [...] Então, trabalhamos com um quadro geral da Teoria da Atividade que vai fazer essa ligação, o que está fazendo todo esse gerenciamento das soluções, da superação, o conjunto de operações difíceis, mas que elas são bem gerenciadas, elas podem gerar a superação de uma ação maior e chegar à conclusão de uma atividade que é a solução desse problema, se o problema tiver sido gerenciado (E1).

E1 indica que o planejamento, isto é, a organização do desenvolvimento de um problema, é realizado tendo como aporte a Teoria da Atividade, com base em Leontiev (1978). Dessa forma, o entrevistado ainda explica que

[...] explicitar e gerenciar o problema é uma atividade do professor, que precisa saber criar, inclusive, o problema, e depois solucioná-lo. $\mathrm{E}$ as ações mediadas dele [problema] em um plano consciente, muitas vezes levam à alteração do inconsciente dos alunos, que são as tarefas colocadas que podem ser os exercícios. Muitas vezes, os alunos confundem os exercícios com o problema. Os exercícios não são problemas. [...] Por isso, acho que a Teoria da Atividade ajuda e que está contida na própria teoria de Vygotsky (E1 - grifo nosso).

É interessante destacar que segundo E1, ao professor compete explicitar e gerenciar o problema; criar e solucionar o problema. São funções que parecem ser ambíguas, uma vez que criar e solucionar o problema remete a atitudes que dependem do planejamento e da atuação dialógica do educador e não apenas do teor do problema formulado. Não obstante, também é importante observar que, segundo o entrevistado, cabe ao professor criar e gerenciar o problema. Como a situação é assimétrica, uma vez que a referência principal para o enfrentamento do problema, nesse caso, é um conceito científico dominado apenas pelo professor, dependeria de sua ação o desencadeamento da Zona de Desenvolvimento Proximal (VYGOTSKY, 2001), e não propriamente a relação problema e conceito científico. Em outros termos, não seria necessariamente função do problema possibilitar a mediação para a apropriação, por parte do estudante, do conceito científico.

Esse aspecto parece ser considerado implicitamente na citação anterior do entrevistado, uma vez que há a necessidade de um planejamento, uma organização do problema a ser abordado em sala de aula, seguindo a atividade, tal como proposta por Leontiev (1978). Isso é fundamental, pois sinaliza que para E1 há a necessidade de um direcionamento, de uma intencionalidade no desenvolvimento de um determinado problema em sala de aula. Tal aspecto está em sintonia com a dinâmica dos Momentos Pedagógicos (DELIZOICOV, 2008, 1991; DELIZOICOV, ANGOT'TI e PERNAMBUCO, 2002), por se configurar como proposta de planejamento dialógico da abordagem de um problema específico no contexto didático-pedagógico. 
O pesquisador E1 também apresenta elementos que sugerem uma relação entre o problema e a atividade, e ao ser questionado sobre a possibilidade de considerar essa articulação na estruturação de um currículo, afirma:

Pode, eu não tinha pensado nisso. [...] Mas esse não é o foco das controvérsias. O foco é trabalhar as controvérsias dentro do currículo posto e o planejamento dessas atividades se dá via atividade. Eu realmente não tinha pensando em organizar o currículo. Eu não vejo isso [relação entre o problema e a atividade] como uma organização curricular, mas sim como parte do fazer pedagógico (E1).

Embora o pesquisador E1 sinalize para a possibilidade da relação entre o problema e a atividade, ele aponta que não havia pensado na possibilidade dessa reflexão constituir a estruturação curricular. Isto é, E1 não centraliza sua preocupação na reestruturação curricular, mas nos artifícios didático-pedagógicos que podem ser utilizados em sala de aula para abordar os conhecimentos científicos e os saberes dos estudantes, também essenciais no processo de ensino-aprendizagem. Para E1, a relação entre problema e atividade se dá no âmbito das controvérsias que parecem se configurar como "enxertos" sem que ocorram alterações na estrutura e organização do currículo tradicional. Tal aspecto apresenta similaridades com uma das modalidades de implementação de Ciência, Tecnologia e Sociedade (CTS), a qual se configura como "enxertos" de temas no currículo com uma ênfase maior no ensino conceitual, sem que ocorram também alterações no currículo tradicional (AULER, 2002).

Em suma, o pesquisador E1 apresenta indicativos de que a escolha do problema, de acordo com a perspectiva vygotskyana, está atrelada e dependente dos conceitos científicos que estão programados para serem abordados no processo de ensino-aprendizagem. Isto é, após serem escolhidos os conceitos, são selecionados os problemas a partir dos quais são planejadas ações didático-pedagógicas.

\section{RESOLUC̣ÃO DE PROBLEMA}

Os trabalhos desse grupo, identificados por Gehlen e Delizoicov (2011) no ENPEC, abordam a noção de problema no contexto de atividades relacionadas à resolução de problemas e exercícios de lápis e papel, com foco na conceituação científica. Em sua maioria, os estudos seguem a linha da Resolução de Problemas (VASCONCELOS et al., 2007), em que alguns exploram os denominados problemas abertos propostos por Gil-Pérez et al. (1992).

Quanto aos critérios utilizados na escolha dos problemas desse grupo, o pesquisador E5 afirma que: "na criação do conceito, o problema é conceitual” (E5), o que remete para o entendimento de que o critério utilizado para a seleção dos problemas segue exclusivamente a conceituação científica. Todavia, na visão de E5, os problemas a serem trabalhados na perspectiva da Resolução de Problemas podem tomar uma dimensão que vai além de exercícios de lápis e papel. Assim, destaca que: 
[...] em Física, normalmente, a gente resolve exercício, a criança ou jovem vai se acostumando a resolver tipos de exercícios, e o problema é aquilo que você se defronta com ele e tem capacidade de levantar hipótese, discutir com outras pessoas em busca de uma solução (E5 - grifo nosso).

Nessa passagem, E5 busca explicitar que os exercícios são atividades diferenciadas dos problemas. Autores que fazem parte da "linha" Resolução de Problemas realizam essa distinção entre problema e exercícios, apontando que "um problema é, de certa forma, uma situação nova ou diferente do que já foi aprendido, que requer a utilização estratégica de técnicas já conhecidas" (ECHEVERRÍA e POZO, 1998, p. 16) e os exercícios de lápis e papel podem tornar-se uma repetição mecânica, não gerando novos desafios para os estudantes. Embora E5 não apresente argumentos nessa linha para a distinção entre problema e exercício, compreende que o problema tem a potencialidade de gerar diversas proposições, promovendo um momento dialógico entre os sujeitos. Ao mencionar o aporte teórico utilizado em seus estudos relacionados à Resolução de Problemas, E5 explica:

[...] eu me baseei na questão dos problemas, não só em Vygotsky, mas também no Bachelard, que diz que todo o conhecimento é resposta a uma pergunta. Então, [...] isso quer dizer que "todo o conhecimento é gerado pela solução de um problema" (E5).

O pesquisador traz à tona um aspecto importante no contexto da noção de problema que se refere à dimensão epistemológica. $\mathrm{O}$ fato de fazer referência a $\mathrm{Ba}$ chelard ilustra o redimensionamento do caráter apenas conceitual para uma visão mais epistemológica do problema, remetendo para a sua importância na produção e apropriação de conhecimento. Essa menção ao problema no contexto da configuração dada por Bachelard indica que pode haver alguma sintonia com a noção de problema presente na obra de Vygotsky, como explicita E5 ao ser indagado sobre essa possibilidade:

Eu acho que sim. Porque, da mesma forma, se o conhecimento para Bachelard surge da resposta a uma pergunta que você propõe, que você faz a si próprio ou a outro, e Vygotsky diz a mesma coisa "que só com o resultado de um problema é que surge o conceito", você tem pelo menos uma convergência entre esses dois autores (E5).

E5, ao sinalizar uma possível relação entre Vygotsky e Bachelard, indica que, na perspectiva vygotskyana, o problema também apresenta uma dimensão epistemológica; aspecto que está em sintonia com a configuração do problema apresentada nas obras de Vygotsky, segundo estudo de Gehlen (2009). Todavia, essa noção de problema, de acordo com a visão epistemológica, não é contemplada por E5 em seus estudos publicados no ENPEC, o que pode ser considerado uma nova concepção quanto à função e à noção desse tema na visão de pesquisadores que seguem a linha Resolução de Problemas.

Quanto à possibilidade dos fragmentos da obra de Vygotsky, presentes no Quadro 2, terem alguma relação com os critérios adotados na escolha dos 
problemas, isto é, com a conceituação científica, E5 novamente retoma a possibilidade da interlocução entre o pensamento de Vygotsky e o de Bachelard (1977) no que concerne à função do problema ser a gênese, o ponto de referência da produção de conceitos científicos.

Ainda acerca dos fragmentos da obra de Vygotsky presentes no Quadro 2, E5 destaca a importância das interações entre os estudantes:

No outro pedacinho de Vygotsky, na terceira frase: “a superar a ação impulsiva, a planejar uma solução para um problema antes de sua execução e a controlar seu próprio comportamento". [...] as crianças realmente constroem hipóteses, concordam e discordam da hipótese do outro [...] até que elas mesmas vão negociando essas hipóteses [...] de construir uma solução comum (E5).

Segundo E5, o processo de resolução de um problema específico envolve uma atividade que potencializa a interação coletiva dos estudantes, que passa a ser um dos aspectos fundamentais a ser considerado durante a solução de problema.

Em suma, o pesquisador E5 compreende que a escolha do problema que estrutura atividades didático-pedagógicas está vinculada aos conceitos científicos que estão planejados para serem trabalhados em sala de aula. Isto é, os problemas são selecionados em função dos conceitos. No entanto, o pesquisador E5 apresenta elementos que se diferem do grupo Interações discursivas, uma vez que chama a atenção para a possibilidade da função do problema em Vygotsky estar na mesma perspectiva de Bachelard (1977), sinalizando para uma interlocução entre ambos os referenciais.

\section{SITUAC̣̃̃ES DE VIVÊNCIA}

Esse grupo, identificado nos trabalhos do ENPEC, realizou estudos que também fazem referência à noção de problema relacionada à conceituação científica. Contudo, os trabalhos abordam aspectos relacionados a situações que envolvem o cotidiano dos estudantes que, na maioria das vezes, são simuladas (GEHLEN e DELIZOICOV, 2011). Já o pesquisador integrante desse grupo, ao ser questionado sobre os critérios utilizados na seleção de problemas, destaca a importância da discussão de questões que, geralmente, estão ausentes no cotidiano dos estudantes, e aponta que:

[...] discutir o que significa a "água mineral ser pura ou não" não está posto na concepção cotidiana, mas o modo de olhar da Química para a questão da pureza introduz a novidade, introduz aí alguma coisa que não era problemática e passa a a ser, que é esse estranhamento com as situações cotidianas que tem, acho, muito a ver com Paulo Freire (E2 - grifo nosso).

O pesquisador revela a potencialidade de uma situação que faz parte do dia a dia de um determinado aluno, como o questionamento sobre a pureza da água mineral, para a abordagem de conceitos químicos em sala de aula. São os conceitos 
científicos, na visão de $\mathrm{E} 2$, responsáveis por trazerem à tona um problema. Nesse caso, a noção de problema não está relacionada à pureza ou impureza da água, mas à nova abordagem a partir dos conceitos químicos. Isto é, E2 conduz a interpretação de que uma situação que faz parte da realidade dos estudantes se tornará um problema desde que possam ser trabalhados conceitos científicos específicos. Desse modo, para o pesquisador E2, uma situação é configurada como um problema quando há uma relação dicotômica entre os conceitos científicos e os cotidianos, o que caracteriza a situação de estranhamento.

Também é importante destacar a menção explícita de E2 ao pensamento de Paulo Freire, quando se refere à questão de se tornar problemática uma determinada situação para os estudantes. De fato, essa ideia pode apresentar similaridade com a concepção educacional de Freire (1987), em especial no que diz respeito ao processo de descodificação ${ }^{2}$, em que o sujeito passa a perceber e interpretar um problema que antes não era visto como tal. Contudo, é preciso ter cuidado com tal relação, uma vez que a situação de estranhamento parece estar subordinada a uma definição anterior dos conceitos científicos elencados, aspecto que diverge da proposta de Freire (1987). Nesta, são temas geradores e não conceitos científicos que estruturam a abordagem didático-pedagógica. Os conceitos científicos são selecionados e elencados na programação como consequência da escolha dos temas, e são eles necessários para a melhor compreensão (DELIZOICOV, 1982; 1991; 2008).

Quanto ao processo de escolha das situações de estranhamento, o pesquisador E2 aponta para a importância de dois critérios:

\footnotetext{
Na escolha dessas situações nós trabalhamos com duas coisas: a primeira é um pouco do próprio delineamento da ciência, isto é, que coisa nos permite contextos, situações de vivência que nos aproximam dos modelos das ciências ou criam essa situação. Um diálogo com a ciência, por exemplo, como os sais minerais, que constituem parte do nosso corpo, é alguma coisa que mobiliza a sétima série. [...] a segunda são situações em que o próprio contexto solicita, mesmo que as questões do aspecto conceitual sejam menos fortes, 0 próprio contexto pela dimensão da sociedade contemporânea, enfim, ela já tem em si alguma coisa que precisa ser vista [...] Então, as coisas relativas às questões ambientais, toda a polêmica da relação entre efeito estufa e aquecimento global, as questões da clonagem, célula-tronco, enfim, que estão de algum modo postas na mídia, as quais são reconfiguradas não como um chavão ou como apenas um bordão da mídia, mas como um problema de fato que mobiliza o estudante na busca por um posicionamento (E2 - grifo nosso).
}

O primeiro critério exposto por E2 está relacionado à dimensão científica, em que as situações da vivência dos estudantes são selecionadas a partir dos modelos da ciência, dos conceitos científicos propriamente ditos. O segundo critério explicitado é o contexto em que vivem os estudantes, isto é, situações presentes na vivência dos estudantes que estão presentes na mídia. A caracterização dessa escolha pode apresentar sintonia com os objetivos do movimento CTS no contexto educacional (SANTOS e MORTIMER, 2000), sobretudo quando E2 aponta para a importância de se explorar um problema que "mobiliza o estudante na busca por um posicionamento”, o que pode convergir com a importância da 
"tomada de decisões responsáveis sobre questões de ciência e tecnologia na sociedade" (SANTOS e MORTIMER, 2000, p.4).

Quanto aos critérios de seleção do problema, E2 também destaca a necessidade de se considerar as seguintes dimensões: social, científica e pessoal. Tal relação é exemplificada pelo entrevistado ao se referir à escolha da situação de estranhamento que envolve a abundância e a falta da água:

[...] do ponto de vista social, é óbvio que tanto o excesso quanto a falta de água são problemáticos. A catástrofe, as enchentes, inundações e a seca são problemas e a gente sempre fica se perguntando o que está acontecendo. Do ponto de vista científico, modelos que tratam disso são ciclos de água no planeta, as questões da energia, enfim, no planeta. Do ponto de vista pessoal, é como eu, cidadão, me coloco diante disso, que relação eu tenho com essas coisas, como eu, de algum modo, posso mobilizar outro conhecimento que não apenas o místico e o religioso para lidar com essas situações, para entender o que se passa (E2).

Quando questionado sobre a possibilidade de abordar uma situação problema que envolve esses três aspectos no âmbito do currículo escolar, E2 aponta para a necessidade de uma reorganização curricular com base em temas:

Estamos organizando o currículo a partir de temas. Em Um currículo temático, então, você tem temas, por exemplo, a questão dos caminhos pela água. Desse tema vamos para os conceitos científicos, em que é o contexto que me leva aos conceitos. Na discussão da "ciência na cozinha" desenvolvemos os conceitos de volume, massa, densidade, são conceitos que dificilmente andariam juntos no currículo tradicional. Ou, então, lá no "viajando com segurança", trabalhamos não só com as leis de Newton, mas também com o conceito de pressão para discutir equipamentos de segurança que também, em um currículo tradicional, dificilmente seriam discutidos juntos (E2).

É notória a compreensão do pesquisador quanto à importância do tema como eixo estruturador da abordagem de conceitos científicos. Entretanto, a escolha do tema segue duas direções: "em alguns momentos foi o conceito que nos orientou a montar um tema e em outros momentos foi o tema em uma dimensão mais social" (E2). O pesquisador sinaliza que não há apenas um critério para a escolha do tema a ser desenvolvido em sala de aula, podendo ser a dimensão conceitual ou a social. Destaca-se que nos trechos citados, muito embora E2 não tenha feito menção a Vygotsky, é esse autor que constitui a referência básica dos trabalhos de sua autoria, que foram selecionados na amostra investigada. Além disso, a produção do grupo que ele coordena tem como fundamentação teórica explicitada o referencial vygotskyano.

É importante enfatizar a concepção do pesquisador do grupo Situações de vivência quanto à necessidade da organização curricular se basear em temas, compreensão que que vai além das apresentadas nos demais trabalhos do ENPEC desse grupo. Talvez essa nova estruturação curricular esteja inspirada em alguns pressupostos da perspectiva de Freire (1987), uma vez que esse autor foi citado por E2. 
A compreensão de E2 acerca do problema como sendo uma situação de estranhamento apresenta relações com as controvérsias caracterizadas pelo pesquisador E1, do grupo Interações discursivas, que também precisam apresentar uma relação assimétrica entre os conhecimentos cotidianos e os científicos. No entanto, a concepção dos pesquisadores E2 e E1 convergem no que tange ao fato de o problema estar diretamente relacionado à apropriação de conceitos selecionados no programa de ensino. Isto é, a partir de determinados conceitos, selecionam-se situações e problemas para que eles possam ser abordados em sala de aula.

\section{TEMAS TRANSVERSAIS}

Esse grupo identificado no ENPEC também realizou trabalhos que apresentam a noção de problema relacionada com a conceituação científica (GEHLEN e DELIZOICOV, 2011). Todavia, o problema é abordado, nesse caso, no âmbito de temas que estruturam a organização curricular tendo como referência os Parâmetros Curriculares Nacionais (PCNs) (BRASIL, 1998), em que se destaca a organização curricular denominada Situação de Estudo (MALDANER, 2007).

Quanto aos critérios de escolha dos problemas na Situação de Estudo, o pesquisador E3 entende que:

No caso da Situação de Estudo [...] a gente identifica as possibilidades conceituais de explicá-la e entendê-la para, daí, definir o seu escopo, sua base, sua circunferência [...] a gente colocou na Situação de Estudo uma forma de reger a organização curricular, mas ela parte de uma situação problema, por exemplo, é o arroio ou microbacia que passa no fundo da escola, ou é a questão da mata da biodiversidade, ou o estudo dos animais e plantas, onde eles estão no ecossistema (E3).

$\mathrm{Na}$ visão do pesquisador, o primeiro passo para identificar uma Situação de Estudo envolve a possibilidade da abordagem de determinados conceitos para, depois, definir o problema a ser trabalhado. Essa relação entre problema e conceitos é melhor explicada por E3 quando ele se refere ao estudo de uma microbacia:

O estudo da microbacia é um problema a ser estudado e explicado sob o ponto de vista da ciência, porque nessa situação você tem ecossistema, biodiversidade, ambiente, água, solo, uma série de questões que precisam ser compreendidas, mas não compreendidas simplesmente com uma listagem de conceitos, mas uma listagem de conceitos que te auxiliam a compreender o problema da microbacia que pode estar poluída, infestada de parasita, de lixo (E3).

A justificativa da escolha do problema, identificado como microbacia, está na possibilidade de esse assunto abranger uma diversidade de conceitos, isto é, quanto maior a variedade de conceitos que podem ser trabalhados nessa situação, maior a possibilidade de ela representar uma situação problema. Também é importante destacar que para E3 a organização dos conceitos não segue uma hierarquia, mas a necessidade de compreensão do problema que, no exemplo acima, está relacionado à poluição da microbacia. Além disso, o pesquisador E3 aponta que: 
[...] não é simplesmente você listar um conjunto de conceitos que vai fazer com que você escolha a situação A ou B, mas sim, são as possibilidades de relações entre esses conceitos que ajudam a compreender aquela situação problema, que fazem com que você a escolha. E aí você vai identificar quais são os principais conceitos para serem discutidos naquele momento. Então o critério de seleção do problema, no meu ponto de vista, é conceitual (E3).

Mesmo explicitado o critério conceitual, uma vez que o pesquisador reconhece que há necessidade de abordar determinados conceitos que contribuem na compreensão de um determinado problema, E3 argumenta que isso não basta. Isso porque além de a situação envolver uma diversidade de conceitos, também é preciso apresentar a possibilidade de eles se relacionarem.

Quanto à possível interlocução desse critério de seleção com as citações de Vygotsky, apresentadas na entrevista (Quadro 2), E3 explica que:

Você vai aprofundar a relação do critério de seleção, que é conceitual, com a questão do problema em Vygotsky. Na solução de um problema você vai dando uma nova explicação, uma nova compreensão, em uma evolução do significado desse conceito, por isso que na solução do problema você vai tendo a possibilidade da formação de um conceito e explicitação desse conceito. [...] A articulação entre os conceitos identificados e o problema é sempre uma relação conceitual (E3 - grifo nosso).

Há uma referência do pesquisador quanto ao processo de significação conceitual durante a resolução do problema. Isto é, E3 chama a atenção para a evolução de significados de um determinado conceito, pois à medida que ele é retomado, passa a adquirir novos significados, aproximando-se, cada vez mais, do conceito abstrato. Nesse caso, é explícito, na compressão de E3, que se privilegia como critério para a seleção dos problemas a dimensão conceitual. No entanto, o pesquisador não explicita outros critérios de seleção de problemas além daqueles de caráter interno à estruturação de conceitos científicos, tal como o da articulação de caráter interdisciplinar, deixando em aberto qual relação teriam com o processo de humanização, presente na obra de Vygostky, tal como discutida por Gehlen (2009).

No entanto, o pesquisador E3 afirma que o critério de escolha dos problemas presentes nos temas baseia-se nos conceitos científicos que necessitam ser trabalhados em sala de aula, desde que estes permitam um número significativo de relações com outros conceitos. Há indicativos de que ao estruturar o conteúdo programático a partir de temas, o pesquisador parece entender o problema como um artifício que organiza, segundo uma perspectiva interdisciplinar, a atividade didático-pedagógica, para abordar conceitos específicos.

\section{PROBLEMA COMO SELEC̣ÃO E ESTRUTURAC̣ÃO DE CONCEITOS}

Esse grupo reúne trabalhos que também configuram o problema na dimensão conceitual. No entanto, diferente dos demais, fazem referência à função 
do problema no processo de escolha e sistematização de determinados conceitos científicos a serem trabalhados em sala de aula (GEHLEN e DELIZOICOV, 2011).

Já a entrevista com um dos pesquisadores desse grupo revelou que a escolha de um problema necessita estar vinculada à vivência dos sujeitos envolvidos no processo educacional: "Quer dizer o problema, quando eu falo significativo, ele tem que ter um enraizamento na vivência das pessoas, e essa vivência se dá nos três planos: naquilo que ela faz, naquilo que ela quer, naquilo que ela se imagina como pessoa atuando (E6)". Esses três planos estão relacionados com o que o pesquisador denomina de dimensões afetiva, cognitiva e social, as quais necessitam ser levadas em consideração ao se falar em significado:

[...] o significado, não só do ponto de vista racional, mas do ponto de vista também da emoção que aquelas questões suscitam. E, então, aí você pode abarcar várias dimensões tanto as de natureza mais cognitivas, como as afetivas, como as questões ligadas mais aos interesses sociais. Como, por exemplo, nesse nosso trabalho, tudo isso se dava no processo de negociação dentro da escola, em um grupo de professores de ciências. Então, à medida que o grupo ia trabalhando nas aulas de ciências, as questões iam surgindo, e aí iam sendo negociadas. Então, por exemplo, dentro da perspectiva de discutir alguns fenômenos de Física, na quarta série, elas começaram a pensar: "bom o que a gente pode ensinar?" E aí chegaram que seria muito interessante discutir, por exemplo, como ensinar o arco-íris (E6 - grifo do autor).

Ao ser questionado sobre como as dimensões afetiva, cognitiva e social foram consideradas na seleção dos conhecimentos que envolvem o assunto "arco-íris", E6 afirmou que:

Olha, eu acho que para te responder com detalhes eu preciso fazer uma análise minuciosa das discussões que se deram no grupo. Nós não fizemos uma análise sobre essas discussões, mas elas estão imbricadas totalmente. Isto é, em uma mesma situação, em um mesmo contexto, você vê essas três dimensões, dependendo do ângulo que você olha (E6).

A resposta do pesquisador não explicita os critérios estabelecidos para a escolha da discussão acerca do "arco-íris". Ele aponta a questão das dimensões afetiva, cognitiva e social, mas, ao se reportar para o contexto escolar, estas não são explicitamente consideradas. Permanece, assim, a questão relativa à característica desses problemas abordados no âmbito escolar e os critérios de sua escolha. Apesar de o pesquisador não esclarecer tais aspectos, enfatiza-se que durante a entrevista, na tentativa de articular as dimensões afetiva, cognitiva e social com os fragmentos da obra de Vygotsky, apresentados no Quadro 2, E6 aponta que:

Eu acho que o problema é o foco principal que explica o processo de formação dos con-

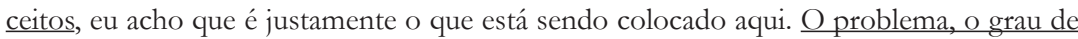
significacão do problema, vai dar a energia para ocorrer esse processo. O motivo, falando em Leontiev, você só se move, você só sai do lugar, se você tiver uma situação problemática profundamente enraizada, cheia de significados. E à medida que você se move, você vai articular todos os seus elementos internos e externos da cultura, e aí você vai elaborar novas ideias, a formação dos conceitos (E6 - grifo nosso). 
Há uma compreensão, por parte de E6, quanto ao fato de o problema, na perspectiva vygotskyana, ser o protagonista no processo de formação dos conceitos, o que indica que sua concepção está próxima da dimensão epistemológica da noção de problema na organização da ciência, sendo ele considerado a gênese da produção de novos conceitos científicos (BACHELARD, 1977).

$\mathrm{Na}$ passagem acima, convém destacar que E6 indica a possibilidade da relação entre problema e motivo na resolução de uma determinada situação-problema. De certa forma, isso se aproxima do processo de humanização descrito por Vygotsky, em que o enfrentamento de um problema envolve um motivo, uma finalidade, para que possa gerar a necessidade de seu enfrentamento (GEHLEN, 2009). Essa relação também indica a possibilita de articulações entre as ideias de Leontiev (1978), no que concerne à Teoria da Atividade, e a dimensão epistemológica do problema em Vygotsky.

Em síntese, E6 apresenta elementos que contribuem para a configuração do problema de acordo com uma dimensão epistemológica, em especial quanto ao fato de o problema apresentar uma relação com o processo de formação de conceitos e com a estruturação de práticas educativas. Essa compreensão, embora se diferencie dos demais grupos, permeia apenas as discussões teóricas dos estudos e do pesquisador, estando ausente das atividades pedagógicas realizadas em sala de aula.

\section{ALGUMAS CONSIDERACְ̃̃ES}

As entrevistas com os pesquisadores indicam que os critérios utilizados para a escolha de problemas que orientam atividades didático-pedagógicas no ensino de ciências estão calcados, em sua maioria, na conceituação científica. Isto é, em uma problemática de dimensão conceitual na qual os problemas são subordinados aos conceitos científicos. Dessa forma, a noção de problema parece não estar suficientemente bem definida, ou seja, não é explicitada sua relação com o processo de humanização, tal como acontece na obra de Vygotsky (GEHLEN, 2009), ainda que sua função pareça estar seguindo um processo de transição em que o problema passa a ter um papel na seleção e estruturação de conceitos científicos, a exemplo da posição do pesquisador representante do grupo Problema como seleção $e$ estruturação de conceitos. Tal aspecto também passa a fazer parte da argumentação do pesquisador representante do grupo Resolução de problemas, ao fazer referência à relação entre o pensamento de Vygotsky e o de Bachelard, no que concerne à gênese da formação de conceitos científicos.

Esse movimento de transição, que ocorre também em opções que não se fundamentam apenas em Vygotsky, pode ser constatado no ensino de ciências em iniciativas que buscam considerar o papel do problema como mediador e organizador de atividades didático-pedagógicas, a exemplo de reorganizações curriculares pautadas na abordagem de temas. Dentre estas, destacam-se aquelas envolvendo o enfoque CTS (AULER, DALMOLIN e FENALTI, 2009; SANTOS, 2008; 
SANTOS e MORTIMER, 2000), a perspectiva freireana (LINDEMANN, 2010; TORRES, 2010; SILVA, 2004; DELIZOICOV, ANGOT'TI e PERNAMBUCO, 2002; DELIZOICOV, 1982) e os Temas Transversais propostos pelos PCNs (BRASIL, 1998). Ou seja, há um movimento no ensino de ciências que busca uma reconfiguração curricular, baseada em temas que apresentam problemas sociais de dimensão científica e tecnológica, bem como situações que envolvam questões sociais vivenciadas pela comunidade escolar e pela sociedade, em geral.

Outro aspecto a destacar é a relação que alguns entrevistados estabelecem entre os fragmentos da obra de Vygotsky, apresentados durante a entrevista, e as ideias de Leontiev (1978), em especial quanto aos aspectos que envolvem a Teoria da Atividade, a exemplo do motivo e da atividade. Nesse sentido, é preciso investigar as relações entre a dimensão epistemológica do problema em Vygotsky e a Teoria da Atividade proposta por Leontiev (1978). Isso porque estudos no ensino de ciências apontam significativas contribuições da Teoria da Atividade, como as que envolvem a formação inicial e continuada de professores (RODRIGUES e MATTOS, 2010; AZEVEDO e ABIB, 2007) e a noção de contexto no ensino de ciências/Física (RODRIGUES e MATTOS, 2007).

Em suma, ressalta-se que as pesquisas em educação em ciências, que se referenciam em Vygotsky, buscam de alguma forma valorizar aspectos que podem fazer parte da realidade dos educandos. No entanto, as entrevistas com os pesquisadores e os trabalhos publicados nas seis primeiras edições do ENPEC (GEHLEN e DELIZOICOV, 2011) revelam que o ponto de partida no processo educacional, com base em um problema de dimensão epistemológica, está sendo pouco explicitado pela pesquisa em ensino de ciências, com aporte nas ideias de Vygotsky. A maioria das pesquisas tem como referência a conceituação científica, ficando a definição e o papel do problema no processo pedagógico, de modo geral, subordinado à escolha dos particulares conceitos eleitos para serem abordados. Chama-se a atenção para o fato de que não se trata simplesmente de elencar problemas que envolvam conceitos cotidianos, mas de fazer emergir um problema que precisa ser enfrentado e cuja formulação possa levar a conceitos novos, em que a apropriação é mediada pelos signos.

\section{NOTAS}

\footnotetext{
${ }^{1}$ Detectou-se que o termo problematização apresentou um caráter polissêmico acentuado. Há indicativos de diversas interpretações dos estudiosos vygotskyanos sobre esse termo envolvendo a relação problema-conceito (GEHLEN, 2009). Será preciso ampliar a análise do grupo "problematização" envolvendo também publicações em periódicos, dissertações e teses, e incluir mais pesquisadores nas entrevistas para a constituição de uma amostra. Pretende-se realizar esse aprofundamento em um outro estudo.

2 Terceira etapa da Investigação Temática, sistematizada por Delizoicov (2008), com base em Paulo Freire, em que são realizados os diálogos descodificadores em torno das contradições sociais em que vivem os sujeitos que fazem emergir os temas geradores.
} 


\section{REFERÊNCIAS}

AULER, D.; DALMOLIN, A. M. T.; FENALTI, V. Abordagem temática: temas em Freire e no enfoque CTS. Alexandria: Revista de Educação em Ciência e Tecnologia, Florianópolis, v.2, n.1, p.67-84, 2009.

AUTH, M. A,; MALDANER, O.A.; PANSERA-DE-ARAÚJO, M.C. et al. Compreensão das ciências naturais como área de conhecimento no ensino médio - Conceitos Unificadores. In: ENCONTRO NACIONAL DE PESQUISA EM EDUCAÇÃO EM CIÊNCIAS, 5., 2005, Bauru/SP. Atas... Bauru: ENPEC, 2005.

AZEVEDO, M. N.; ABIB, M. L. S. Aprender e ensinar Ciências no continuum da docência. In: ENCONTRO NACIONAL DE PESQUISA EM EDUCAÇÃO EM CIÊNCIAS, 6., 2007, Florianópolis. Atas... Florianópolis: ENPEC, 2007.

BACHELARD, G. O racionalismo aplicado. Rio de Janeiro: Zahar, 1977.

BRASIL. Ministério da Educação. Secretaria de Educação Fundamental. Parâmetros Curriculares Nacionais: Ciências da Natureza. Terceiro e Quarto Ciclos. Brasília: MEC, 1998.

CIRINO.M.M.; SOUZA, A.R. O tratamento probabilístico da teoria cinética de colisões em livros de Química brasileiros para o ensino médio. Revista Electrónica de Enseñanza de las Ciências, Vigo, ES, vol. 9, n.1, 125-144, 2010.

DELIZOICOV, D. Concepção problematizadora do ensino de ciências na educação formal. 1982. Dissertação (Mestrado) - Faculdade de Educação da Universidade de São Paulo, São Paulo, 1982.

DELIZOICOV, D. La Educación en Ciencias y la Perspectiva de Paulo Freire. Alexandria - Revista de Educação em Ciência e Tecnologia, Florianópolis, v.1, n.2, p.37-62, 2008. Disponível em: <http://www. ppgect.ufsc.br/alexandriarevista/index.htm>. Acesso em: 10 mar. 2012.

. Conhecimento, Tensões e Transições. 1991. Tese (Doutorado). Faculdade de Educação, Universidade de São Paulo, São Paulo, 1991.

DELIZOICOV, D.; ANGOTTI, J. A.; PERNAMBUCO, M. M. Ensino de Ciências: fundamentos e métodos. São Paulo: Cortez, 2002.

ECHEVERRÍA, M. P. P.; POZO, J. I. Aprender a resolver problemas e resolver problemas para aprender. In: POZO, J. I. (org.). A solução de problemas: aprender a resolver, resolver para aprender. Porto Alegre: Artmed,1998. p.13-42

FREIRE, P. Pedagogia do Oprimido. 17 ed. Rio de Janeiro: Paz e Terra, 1987.

FREITAS, M. T. de A. O pensamento de Vygotsky nas reuniões da ANPED (1998-2003). Educação e pesquisa, São Paulo, v.30, n.1, 2004.

GEHLEN, S. T. A função do problema no processo ensino-aprendizagem de Ciências: contribuições de Freire e Vygotsky. 2009. Tese (Doutorado) - Programa de Pós-Graduação em Educação Científica e Tecnológica, Universidade Federal de Santa Catarina. Florianópolis, 2009.

GEHLEN, S.T.; MACHADO, A.; AUTH, M.A. Freire e Vygotsky no Simpósio Nacional de Ensino de Física. In: SIMPÓSIO NACIONAL DE ENSINO DE FÍSICA, 18., 2009,Vitória/ES. Anais... Vitória: SBF, 2009.

GEHLEN, S.T.; SCHROEDER, E.; DELIZOICOV, D. A Abordagem histórico-cultural no Encontro Nacional de Pesquisa em Educação em Ciências. In: ENCONTRO NACIONAL DE PESQUISA EM EDUCAÇÃO EM CIÊNCIAS. Encontro Nacional de Pesquisa em Educação em Ciências, 6., 2007, Florianópolis. Atas... Florianópolis: ENPEC, 2007.

GEHLEN, S.T.; DELIZOICOV, D. A função do problema na Educação em Ciências: estudos baseados na perspectiva vygotskyana. Revista Brasileira de Pesquisa em Educação em Ciências, São Paulo, v. 11, n.3, 2011

GONÇALVES, F.P.; MARQUES, C.A. Contribuições pedagógicas e epistemológicas em textos de experimentação no ensino de química. Investigag̃ões em Ensino de Ciências, Porto Alegre, v.11, n. 2, 2006. Disponível em: <http://www.if.ufrgs.br/public/ensino/revista.htm>. Acesso em: 02 out. 2012.

GIL-PERÉZ, D. et al. Questionando a didática de resolução de problemas: elaboração de um modelo alternativo. Caderno Catarinense de Ensino de Física, Florianópolis, v.9, n.1, 1992.

LEONTIEV, A. O desenvolvimento do psiquismo. Lisboa: Livros Horizonte, 1978. 
LINDEMANN, R.H. Ensino de Quimica em escolas do campo com proposta agroecológica: contribuições a partir da perspectiva freireana de educação. 2010. Tese (Doutorado) - Programa de Pós-Graduação em Educação Científica e Tecnológica, Universidade Federal de Santa Catarina. Florianópolis, 2010.

MALDANER, O. A. Situações de Estudo no Ensino Médio: nova compreensão de educação básica. In: Nardi, R. (org.). Pesquisa em Ensino de Ciências no Brasil: alguns recortes. Escrituras: São Paulo, 2007. p. 237-253.

MONTEIRO, I. C.C.; GASPAR, A. Um estudo sobre as emoções no contexto das interações em sala de aula. Investigações em Ensino de Ciências, Porto alegre, v.12, n.1, pp. 71-84, 2007. Disponível em: $<$ http://www.if.ufrgs.br/ienci/artigos/Artigo_ID162/v12_n1_a2007.pdf>. Acesso em: 20. ago, 2012.

MORTIMER, E. F.; SCOTT, P. Atividade discursiva nas aulas de Ciências: uma ferramenta sociocultural para analisar e planejar o ensino. Investigações em Ensino de Ciências, Porto Alegre, v.7, n.3, 2002.

MORAES, R.; GALIAZZI, M. C. Análise Textual Discursiva. Ijuí: UNIJUÍ, 2007.

OSTERMANN, F. CAVALCANTI , C. J. H.; PRADO. et al. Fundamentos da física quântica à luz de um interferômetro virtual de Mach-Zehnder. Revista Electrónica de Enseñanza de Ciências, Vigo, ES, V.8, n.3, 2009.

PEREIRA, A.P.; OSTERMANN, F.; CAVALCANTI, C. J. H. A ocorrência de 'fala privada' entre adultos: uma estratégia analítica para o estudo das funções intrapsicológicas no ensino de ciências. Ensaio. Pesquisa em Educação em Ciências. Belo Horizonte, v. 13, n.1, 2011.

RODRIGUES, A. M.; MATTOS, C. R. Reflexões sobre a noção de significado em contexto. INDIVIS A - Boletín de Estudos e Investigación, Madrid, ES, v.7, 323-331, 2007.

RODRIGUES, A. M.; MATTOS, C. R. A disciplina de práticas de ensino: um olhar sócio-histórico-cultural. In: ENCONTRO DE PESQUISA EM ENSINO DE FÍSICA, 12., 2010, Águas de Lindóia. Anais... 2010.

SANTOS, W.L.P. Educação científica humanista em uma perspectiva freireana: resgatando a Função do ensino de CTS. Alexandria, v.1, n.1, p. 109-131, mar. 2008. Disponível em: < http://www. ppgect.ufsc.br/alexandriarevista/index.htm>. Acesso: 02 mar. 2012.

SANTOS, W.L.P.; MORTIMER, E. F. Uma Análise de Pressupostos Teóricos da Abordagem C-T-S (Ciência-Tecnologia-Sociedade) no Contexto da Educação Brasileira. Ensaio. Pesquisa em Educação em Ciências, Belo Horizonte, v.2, n.2, 2000, p. 133-162.

SOARES, N.; AGUIAR. O. O uso dos conceitos de elemento e substância por estudantes do ensino fundamental: uma perspectiva de análise sociocultural. Revista Brasileira de Pesquisa em Educação em Ciências, São Paulo, v. 8, n.3, 2008.

SARMENTO, D. F. A Teoria Histórico Cultural de L.S. Vygotsky no Brasil: uma análise da produção acadêmica e científica no período de 1986 a 2001. Orientador: Hugo Otto Beyer. 2006. Tese (Doutorado em Educação) - Universidade Federal do Rio Grande do Sul, Porto Alegre, 2006.

SILVA, F.G.; DAVIS, C. Conceitos de Vigotski no Brasil: produção divulgada nos Cadernos de Pesquisa. Cadernos de Pesquisa, São Paulo, v. 34, n. 123, p. 633-661, 2004.

TORRES, J.R. Educação Ambiental crítico-transformadora e Abordagem Temática. Tese (Doutorado em Educação Científica e Tecnológica) - Programa de Pós-Graduação em Educação Científica e Tecnológica, Universidade Federal de Santa Catarina. Florianópolis, 2010.

TORRES, J. R. et.al. Ressignificação curricular: contribuições da Investigação Temática e da Análise Textual Discursiva. Revista Brasileira de Pesquisa em Educação em Ciências, São Paulo, v. 8, n.2, 2008, p. 1-13. VASCONCELOS, C. et al. Estado da arte na resolução de problemas em Educação em Ciência. Revista Electrónica de Enseñanza de las Ciências, Vigo, ES, vol. 6, n. 2, 235-245, 2007. Disponível em:< http://www.saum.uvigo.es/reec/> Acesso em: 21 set. 2012.

VYGOTSKY, L. S. A Construção do Pensamento e da Linguagem. São Paulo: Martins Fontes, 2001. - A Formação Social da Mente. 6. ed. São Paulo: Martins Fontes, 1998.

. Pensamento e Linguagem. 3. ed. Trad. Jefferson Luiz Camargo. São Paulo: Martins Fontes, 2005.

Data de Recebimento: 20/06/2011

Data de Aprovação: 21/12/2011

Data da Versão Final: 22/01/2013

Revista Ensaio | Belo Horizonte | v.15 | n. 02 | p. 45-63 | maio-ago | 2013 